\title{
De la ecología urbana al poder local (cinco décadas de estudios urbanos) *
}

\author{
ALICIA ZICCARDI
}

\section{INTRODUCCIóN}

Una revisión de la producción académica publicada en la Revista Mexicana de Sociología que toma lo urbano como objeto de estudio es muy fructífera. En primer lugar porque permite recuperar la presencia de autores y textos cuya existencia fue de gran importancia para la comprensión de los fenómenos urbanos, tanto desde una perspectiva teórica como del análisis de la realidad social. En segundo lugar, porque señala la necesidad de que la investigación en este campo del conocimiento dé cuenta del estado de las artes al construir proposiciones e interpretaciones que, aun siendo sustantivas, no sabemos cuánto y cómo avanzan en la interpretación de la sociedad global.

En México, la investigación urbana en general y la sociología urbana en particular han realizado pocos trabajos de revisión del estado del conocimiento sobre las diferentes temáticas abordadas con la finalidad de ir confrontando resultados e ideas y enriquecer el quehacer y la investigación de manera colectiva. ${ }^{1}$ Más aún, la actual generación de investigadores dedicados a estudiar lo urbano se formó y comenzó a producir en los setenta y se halla claramente influida por una escuela del pensamiento particular: la sociología urbana francesa (incluídos los españoles) y, en menor medida, algunos representantes de la sociología inglesa. Hay dos hechos determinantes de esta situación: 1) la traducción al español de los textos de la sociología urbana francesa (particularmente Lefebvre, Castells, Borja, Lojkine, Topalov) y 2) el interés que determinados autores de los países centrales han mostrado por el estudio de los fenómenos urbanos (políticos en particular) en América Latina. A aquellos nombres hay que agregar entonces los de los antropólogos y científicos sociales estaduniderises dedicados al estudio de lo urbano (Cornelius, Eckstein, Roberts). Claro que el primes grupo de autores ha ejercido en los latinoamericanos una influencia decisiva en la selección de los temas de investigación, en la adopción de determinada metodología de análisis, en

* Agradezco la colaboración de Sonia Bass Zavala en el trabajo de revisión bibliográfica de este artículo.

1 Entre estos trabajos pueden citarse: Roberto Donoso (1987); Antonio Azuela y Emilio Duhau (1987); Alicia Ziccardi y Homero Saltalamacchia (1980); Alicia Ziccardi (1988); Rosemond Cheetham (1984). 
la apropiación y confrontación de conceptos y categorías teóricas y en los propios resultados de investigación obtenidos.

Este trabajo intenta presentar una revisión bibliográfica de los textos publicados en la Revista Mexicana de Sociología desde finales de los años treinta hasta la actualidad. Creemos que la Revista expresa claramente la evolución de temas y métodos científicos adoptados por la comunidad académica internacional estudiosa de los procesos urbanos de la sociedad, al haber incorporado los trabajos de autores cuya producción ha sido relevante en este campo del conocimiento.

Tres son las grandes corrientes del pensamiento teórico y de la investigación urbana que se suceden en el tiempo y que orientan sus esfuerzos hacia el estudio de determinados temas de investigación, aquellos socialmente problematizados en cada período: 1) La escuela de Chicago con sus estudios de ecología humana y de la comunidad; fundadores de una especialidad dentro de la sociología estadunidense, la sociología urbana, desde mediados de los años veinte; 2) Los estudios sobre urbanización que se realizan desde fines de los cincuenta dentro del pensamiento funcionalista y continuan siendo un núcleo de análisis central en las sociologías del cambio, la dependencia y la marginalidad desarrolladas en América Latina durante la década siguiente, y 3) los estudios de los problemas urbanos que se inscriben en el marco teórico del materialismo histórico de la sociología urbana francesa. En esta producción adquieren centralidad las temáticas relacionadas con la estructura y las políticas urbanas y los movimientos sociales urbanos. Esta línea de investigación en años recientes ha incorporado nuevos temas de estudio tales como los procesos de reestructuración territorial del Estado, las políticas de descentralización y el fortalecimiento de los poderes locales y los efectos espaciales de la revolución tecnológica en el campo de la informática.

\section{Ecología uRbana y comunidad}

Desde mediados de los años veinte la sociología urbana ganó un espacio académico institucional en la Universidad de Chicago al desarrollar un conjunto de investigaciones teóricas y empíricas que intentaban aplicar los principales conceptos e ideas de las ciencias naturales al análisis de la organización social del medio urbano. Con ello se trataba de otorgar contenido social a los desarrollos de la llamada ecología humana. Robert E. Park es quien promueve un conjunto de investigaciones cuyo objeto de estudio es la ciudad y los efectos sociales que producen los procesos de urbanización. Ernest Burguess, Mc Kenzie, Louir Wirth, G. H. Mead, F. Merrill y Robert Redfield son, entre otros, los principales representantes de esta escuela que logran que la sociología urbana se constituya en una especialización.

El contexto en el cual se desarrollan estos estudios es principalmente 
la ciudad de Chicago, con una elevada tasa de crecimiento poblacional, "laboratorio social" parkiano en el que los fenómenos y comportamientos sociales conflictivos son componentes presentes en el escenario social. Pero la sociología urbana del periodo de la gran crisis da cuenta también de otros estudios como los de los de Helen y Robert Lynd, que realizan profundas investigaciones en comunidades locales.

La sociología estadunidense transita en esos años hacia la elaboración de un cuerpo teórico cuyo producto más acabado es el marco funcionalista parsoniano. Es clara la influencia de los clásicos (Durkheim, Weber, Simmel) en esta sociología estructural funcionalista en la cual la díada conflicto social-restauración del equilibrio es una preocupación permanente. La ciudad entonces es el espacio de análisis privilegiado para los estudios sobre las causas y características de los procesos de desorganización social y de las instituciones encargadas de atenderlos.

La principal crítica que se formuló a esta producción académica es el identificar ciudad y sociedad, con lo cual se cuestiona la propia especificidad del análisis (cfr. Bettin, 1982: 72-73). Castells sostuvo que un examen de los trabajos de la Escuela de Chicago demuestra que: "su tema central no es tanto 'todo lo que sucede en la ciudad' como ( $y$ no hacemos más que recordar un hecho ya conocido) los procesos de desorganización social e inadaptación individual, la persistencia de ciertas subculturas autónomas, desviantes o no, y su resistencia a la integración" (Castells, 1976a: 21).

La Revista Mexicana de Sociología permite conocer muchos trabajos sociológicos importantes en la época y también da cabida a la producción de los representantes de la Escuela de Chicago y sus seguidores. En el primer trimestre de 1942 se publica una colaboración especial de Robert Redfield bajo el título de "La sociedad folk". Es una reflexión que signará la investigación en la antropología y la sociología, rural y urbana. En ese trabajo, Redfield presenta los rasgos de una sociedad folk ideal, en contraposición a los rasgos de las sociedades modernas. La sociedad folk es pequeña, aislada, con mecanismos de transmisión de conocimientos orales; donde hábitos y costumbre son la misma cosa y con un gran sentido de solidaridad de grupo; con pocos instrumentos disponibles; con un bajo grado de división social del trabajo (en el sentido Durkheimiano); una cultura entendida como organización e integración de comportamientos convencionales, con una moral que persigue un destino colectivo; lugar donde la tradición es una autoridad suficiente y una sociedad integrada por familias más que por individuos.

La principal preocupación de Redfield es el contraste de esta sociedad con la sociedad moderna; contraste que más tarde el autor resolverá con la creación de su "continuum rural-urbano". En aquellas primeras observaciones Redfield capta la persistencia de muchos grupos tribales (por cjemplo, los esquimales del polo, los sedentarios Haida de las islas de la Reina Carlota, las tribus comanches, algunos Estados del Árica Occiden. 
tal, una élite alfabetizada en China en combinación con multitud de comunidades rurales de tipo "folk"). Pero Redfield advierte que existen muchos problemas para la sobrevivencia de estas comunidades cuando se encuentran muy cerca de sociedades modernas. Sus investigaciones en Yucatán le permitieron advertir las diferencias locales de cuatro comunidades a partir del estudio de la naturaleza del festival del santo patrono del pueblo. Las principales distinciones estaban relacionadas con el grado de aislamiento respecto de los "centros urbanos" de influencia; "de influencia modificante" en su lenguaje. Redfield sostiene: "Entonces uno puede darse cuenta de que el festival, dejando de ser un acto sumamente sagrado hecho por la población, en cuanto ésta es una colectividad formada por grupos familiarmente definidos que guardan estrecha relación con el sistema de concepciones morales y religiosas de cada uno, llega a ser principalmente en las comunidades más urbanizadas una oportunidad para el deleite de unos individuos y el provecho financiero de otros, con muy poca relación con las concepciones morales y religiosas" (Redfield, número 4 de 1942). Su principal conclusión es que las comunidades menos aisladas y más heterogéneas de la península son más profanas e individuales y están caracterizadas por una mayor desorganización de su cultura.

Redfield advierte que estas ideas no pueden extrapolarse y sus estudios en algunas comunidades indígenas de Guatemala le permiten mostrar que las características no se repiten y que lo importante es la determinación de las llamadas "condiciones limitantes". Redfield sin duda será uno de los investigadores estadunidenses que ejerce gran influencia en la formación académica de los antropólogos latinoamericanos. Como veremos luego, dos décadas después sus trabajos son objeto de polémica, al ser contrapuestos a los estudios de Óscar Lewis E., y ofrecen ideas fundamentales en la comprensión de la relación campo-ciudad. El continuum folk-urban de Redfield constituye el punto de llegada a una concepción de cambio social (progresivo), a través del cual las sociedades folk atraviesan por un proceso de mutación y, en diferentes etapas de su desarrollo, van incorporando características del tipo urbano-moderno como dimensión, densidad, heterogeneidad. Esta viva presencia de Redfield en la Revista Mexicana de Sociología no es comparable con la de otros miembros de la Escuela de Chicago. Sin embargo, los conceptos e ideas de la Escuela de Chicago ejercen una fuerte influencia durante varias décadas, lo cual se advierte en los trabajos de diferentes sociólogos estadunidenses y latinoamericanos que son difundidos en nuestra Revista. Robert Park, en particular, es un autor que tiene esta presencia indirecta en los primeros años de existencia de la publicación. Park había logrado atraer la atención pública y el reconocimiento académico de sus trabajos y de los de sus seguidores. Un colega de Northwestern University, Ernest Mowrer publica en 1943 un ensayo sobre "El estudio ecológico de la ciudad". En el mismo presenta a Park como un sociólogo que atraja la atención sobre 
ciertos aspectos de la vida de la comunidad que necesitaban ser remediados. Mowrer sostiene: "Sin embargo, Park nunca fue un buen reformador. El estudio de los asuntos sociales lo convenció de que lo que se necesitaba no era el entusiasmo del reformador que hurga en los barrios bajos de la ciudad para sacar a la luz especímenes que pone a la vista del público, sino la comprensión del proceso que ha producido dichas condiciones. Así, Park llegó a convencerse de que la organización de la ciudad era completamente natural y que primero se debía procurar entenderla y después tratar de cambiarla" (Mowrer, número 1 de 1943). Este autor se preocupa por buscar las influencias que recibió Park de las obras de geografía humana, Brunhes, Semple, Ratzel, entre otros, que le abrieron camino pero le mostraron las falacias del determinismo geográfico que viciaba las interpretaciones, y que plantearon nuevos interrogantes en el campo de la antropología con el cual estaba familiarizado Park. Por ello Mowrer sostiene que con base en los fundamentos de la ecología animal y vegetal de la geografía humana, de la antropología y de la investigación social, Park "se convirtió en la fuente a través de la cual se desarrollaron las concepciones esenciales de la ecología humana: la noción de ciudad como área natural, el modelo de círculos concéntricos de su organización y el proceso ecológico que determina la estructura de la comunidad" (Mowrer, número 1 de 1943). Éstos precisamente son los temas que privilegian los representantes de la Escuela y que desarrollan en sus trabajos.

Park aporta conceptos centrales para los desarrollos teóricos y empíricos que se elaboran entre las dos guerras. Uno es el de competencia, noción biológica de la lucha por la existencia y noción económica de cooperación, que se extiende hasta incluir la lucha por el poder, por el estatus, por la seguridad económica. El otro es el concepto de sucesión, estrechamente ligado al de dominio, entendido como secuencia ordenada de cambios que tienen lugar en la estructura básica de la ciudad cuando pasa de un estado de equilibrio a otro. Y el tercer concepto, que es para este autor el que conduce al problema central de la sociología urbana, es la comprensión de la naturaleza del orden social y de su papel en la determinación de la personalidad. Es aquí donde las fronteras de la sociología urbana respecto a las de la psicología social, las ciencias políticas y la misma antropología son muy difusas. Por ello Mowrer recuerda la crítica ("las falacias", en su lenguaje) que se deben admitir en relación con los estudios ecológicos; unas en relación con el método y otras que surgen del carácter de los datos que se emplean en estos estudios. Respecto al método existe la objeción de que la ecología humana hace resaltar la competencia más como una fase de la biología que de la sociología. De igual forma, organización y desorganización son conceptos asociados a la personalidad. En relación con los datos existen problemas relativos a la falacia de expresar en cifras fenómenos sociales que responden a una amplia gama de procesos; las correlaciones no revelan los procesos básicos que producen los fenómenos sociales. Esto lo lleva a concluir: “...p parece 
que el estudio ecológico proporciona un sistema metodológico de referencia, desde el cual se puede hacer más inteligible la organización de las comunidades urbanas, por cuanto esta organización es el resultado de la acción de fuerzas competitivas. Nadie puede negar que el orden moral se impone como instrumento de dirección y control sobre la subestructura de competencia. Pero también es verdad que cuando las fuerzas competitivas entran en conflicto con la superestructura moral, bajo las modernas condiciones de la vida urbana, la última es la que pierde. Así, la comprensión de esta subestructura básica es esencial para cualquier análisis fundamental de la ciudad" (Mowrer, número 1 de 1943).

Al tiempo en que continúan estudios sobre la ecología urbana, lo local, el estudio de la comunidad, de las relaciones primarias, de las formas de poder, comienzan a ganar importancia y surgen en franca oposición a aquellas perspectivas que, apoyadas en el darwinismo social, prevalecen en el análisis parkiano. La discusión se centra en cuestionar la opinión de Park respecto a que la cultura urbana no tiene un carácter autónomo e independiente de las leyes de la naturaleza. Debe recordarse que las comunidades urbanas son definidas originariamente por Park por la presencia de los siguientes elementos: población, costumbres, creencias, patrimonio de conocimientos tecnológicos, recursos naturales del hábitat. Este es el concepto de comunidad incorporado en un conjunto de importantes investigaciones de campo. En las visiones de "orden y cambio social en la ciudad" es donde se aprecia la influencia de Durkheim en Park, según la cual el hombre nace con instintos, pasiones y apetitos incontrolados y la sociedad impone un orden social concebido como defensa de "civilización” (Bettin, Gianfranco: 1982: 81). Finalmente, el concepto parkiano que va evolucionando dentro de la sociología funcionalista hasta que finalmente adquiere una reinscripción marxista es el de "marginalidad". Estos conceptos y nociones - comunidad, orden, civilización y marginalidad - son parte del cuerpo teórico que se desarrolla inicialmente en el funcionalismo estructural y que, como veremos, se refieren a problemas sociales que estarán presentes en adelante en los estudios urbanos producidos con otros marcos teóricos.

A principios de los años cincuenta, es decir cuando ya la Escuela de Chicago había experimentado en su composición y en su pensamiento profundos cambios, Gino Germani publica en la Revista Mexicana de Saciología (número 3 de 1950) un trabajo titulado: "El estudio integral de las comunidades". Germani es sin duda uno de los principales sociólogos latinoamericanos cuya influencia es decisiva en el análisis social y político de la urbanización. En ese trabajo Germani sostiene que los estudios empíricos de las comunidades han pasado por tres fases. La primera, llamada normativa o valorativa, que va desde la prehistoria de estas investigaciones hasta el movimiento de las social surveys, en la cual el transfondo son los propósitos de mejoramiento social ante los graves problemas de la pobreza, la delincuencia y la desintegración familiar. La 
segunda, que corresponde a la incorporación de elementos de orden tipológico y de la sociología estructural a partir de la recuperación de la metodología weberiana del tipo ideal (tipo urbano y tipo rural) amplificados por C. C. Taylor y L. Wirth. En tercer lugar, el aporte original de la Escuela de Gusti en Rumania, que creó un método de investigación propio y original de las comunidades basado en la cooperación de especialistas de distintas ciencias sociales y sociologías, con el empleo de técnicas como la fotografía y el cine sonoro.

Germani advierte que no existe oposición entre estos distintos métodos y puntos de vista que se han ido sucediendo en los estudios de las comunidades. Sin embargo, señala que uno de los defectos de la sociología estadunidense, de la cual es un profundo conocedor, es "justamente el haber perfeccionado los métodos, olvidando empero la necesidad de vincular cada paso de la investigación con una estructura teórica general, que es lo que en definitiva constituye la ciencia". Este planless empiricism, como fue llamado con feliz expresión, ${ }^{2}$ ha merecido las críticas no sólo de sociólogos extranjeros, sino también de los mismos estadunidenses y existe actualmente una preocupación muy marcada por tratar de corregir esta grave limitación" (Germani, número 3 de 1950).

El autor plantea problemas metodológicos generales de los estudios de comunidades. Expresa su preocupación porque los estudios de comunidades son de manera predominante descriptivos, recordando que los Lynd, en sus pioneros estudios sobre poder local en Middletown, realizaron comparaciones en el tiempo, lo cual enriqueció sus resultados. Según Germani deben realizarse también exámenes paralelos de fenómenos contemporáneos dentro de la misma comunidad o de ciertos aspectos en comunidades distintas. Ello se inscribe en un punto de vista funcional, recuperando la tradición de Malinowski sobre la antropología cultural que en esos momentos influía marcadamente en la metodología sociológica. Vincula esta forma de conocimientos con la intención reconstructiva de Karl Mannheim elaborada para fundamentar la planificación de posguerra, sustituyendo al conocimiento fragmentario prevaleciente hasta entonces en las ciencias sociales. Lo fundamental es que al aplicar al estudio de las comunidades el punto de vista funcional y el conocimiento sociológico reconstructivo advierte otros problemas metodológicos de orden general tales como: a) la necesidad de basar la investigación en un contacto personal directo, lo cual puede lograrse a través de la técnica reconocida como "observación partícipe" y la investigación por equipo, y b) la adopción de una "óptica sociológica especial" que permita colocar al sociólogo en la misma posición que el antropólogo en el estudio de una cultura que no es la propia.

Pero un aporte fundamental de su trabajo es, a nuestro entender, su

2 Germani atribuye esta expresión a W. I. Thomas y F. Znanieck en "The polish peasant in Europe and America", Nueva York, A. Knopf, 1927. 
revisión de las técnicas básicas utilizadas en la investigación de las comunidades. Éstas se refieren a la construcción de muestras representativas para cada uno de los fenómenos a estudiar y a un regreso germaniano al método ecológico. Germani recupera el esquema formulado por Burguess sobre los círculos concéntricos de la gran ciudad y la distribución espacial de los fenómenos sociales en: 1) el centro comercial; 2) la zona de transición, la clase pobre, barrios de inmigrantes de varias nacionalidades, alto grado de desintegración social y crimen; 3) los artesanos, obreros especializados, empleados, en general segunda generación de inmigrantes; 4) la zona de barrios residenciales de clase media y alta, y 5) la zona representada por la periferia que contiene subcomunidades de distinto carácter. Este esquema, difícil de aplicar aún en el análisis de las ciudades estadunidenses, es considerado en la época como portador de cierta validez empírica. Se incorpora el concepto de "gradiente", el cual indica la gradación de intensidad de un fenómeno social dado (por ejemplo la delincuencia) en determinado punto geográfico de la comunidad. El análisis microsociológico, semejante a la ecología como sociometría, es considerado otro de los métodos para estudiar las relaciones interpersonales por medio de imágenes especiales. También las cédulas y cuestionarios son considerados instrumentos fundamentales de la investigación sociográfica. Germani se encargará de aplicar estas técnicas y discutir estos conceptos en sus trabajos de investigación en el Instituto de Sociología de la Universidad de Buenos Aires, siendo también el creador la carrera de sociología en aquella Universidad, años después.

Los estudios sobre la estructura ecológica de las ciudades es la otra línea de investigación que tiene su origen en la Escuela de Chicago. Para el caso de América Latina y de México ofrece instrumentos de análisis interesantes para el estudio de la distribución en el espacio de los fenómenos sociales. Tanto en los años cincuenta como en los sesenta existen varios trabajos que se inscriben en esta línea. Destaca uno de ellos sobre el estudio de la estructura ecológica de las ciudades mexicanas, del cual son autores Floyd y Lillian Dotson (número 1 de 1957). En el mismo se busca responder a la pregunta de si tienen las ciudades, a pesar de sus numerosas y evidentes variaciones individuales, una forma ideal interna, a través de la cual pueden ser descritas. Para ello retoman también la concepción de Burguess construida sobre la base de un tipo ideal weberiano, por considerar que encierra un valor estimulante para el análisis de la estructura de la ciudad no por encerrar validez empírica; sino porque es un medio heurístico. La teoría sobre las zonas concéntricas proporcionó "una imagen conceptual amplia de la estructura interna de las ciudades y del crecimiento urbano, desde un punto de vista sociológicamente importante". Recuerdan que el primer estudio que dentro de esta perspectiva se realizó sobre la ciudad hispanoamericana fue el de Asael Hansen, que publicó una descripción de Mérida en 1934 a partir del cual se pudo comprobar el contrastc entre estas ciudades y el patrón ecológico 
estadunidense porque las zonas están en un orden inverso al advertido por Burguess y sus seguidores. Los Dotson realizaron sus estudios en Guadalajara en 1951 y años después en León, México, Monterrey, Puebla, San Luis Potosí y Veracruz, es decir, las ciudades mexicanas que en 1953 tenían más de 100000 habitantes. El trabajo ecológico contenido en este artículo se refiere a las ciudades de Saltillo, Guadalajara y México, que presentan un interesante material empírico y ofrecen los elementos originales para un análisis urbano comparativo. Lo más interesante en este trabajo es que llegan a la conclusión de que: "Las ciudades mexicanas individuales son tan distintas entre sí como las personalidades humanas. Cada una, a su materia, es diferente a todas las demás". Pero, a pesar de ello, concluyen que es posible elaborar un tipo ideal compuesto por todos esos elementos comunes que convenga a las ciudades reales, mucho mejor de lo que conviene la teoría de Burguess de las zonas concéntricas a las ciudades estadunidenses. Los Dotson destacan finalmente la presencia de un elemento, el factor cultural, que no puede descuidarse en la elaboración de una teoría acerca de la naturaleza de las ciudades.

En esta misma línea de investigación incluímos un trabajo publicado a mediados de los sesenta como colaboración especial de un profesor de la Universidad de Washington, llamado Norman S. Hayner, el cual observa la ciudad de México, desde "su estructura ecológica latinoamericana" (número 1 de 1964). Este autor también retoma el análisis pionero de Hansen sobre Mérida y realiza una revisión histórica de la evolución de la población y la construcción de la ciudad de México buscando explicaciones que fundamenten su primacía (concepto elaborado en la época) sobre las demás ciudades del país. El autor se detiene en señalar que: "El índice más fácil de conseguir sobre la estructura ecológica de la metrópoli es el de los gradientes de valor del terreno. Los valores comerciales que se calculan para los terrenos en 1943 y 1948 se basan en ventas reales, ofertas o demandas. Hayner describe puntos nodales de la ciudad y el comportamiento del mercado inmobiliario, mostrando la forma como distintos sectores sociales se localizan en la ciudad (incluso las llamadas por él "personas distinguidas"). Retoma los resultados de las investigaciones realizadas por el arquitecto Félix Sánchez B. $^{8}$ sobre el problema del alojamiento

3 Según Haynes (número 1 de 1964) "En 1947 el Banco Nacional Hipotecario y de Obras Públicas continuó sus estudios sobre el problema del alojamiento en la ciudad de México, con una investigación realizada por el arquitecto Félix Sánchez B." (1964: 226-227). La publicación de 1949 se titulaba "El problema de la habitación", y el mismo Banco publicó otro trabajo: "Estudio 6, El problema de la habitación en la ciudad de México". El autor también recuerda que Félix Sánchez, en su puesto de oficial mayor del Instituto Nacional de Vivienda realizó un estudio titulado: "Herradura de tugurios" publicado por el Instituto. Incluímos estas referencias porque creemos que las mismas son ejemplos de la importancia que encierra el recuperar la bibliografía existente sobre diferentes temáticas urbanas para enriquecer nuestros análisis actuales. 
en la ciudad de México y expresa su beneplácito por la construcción del conjunto habitacional más grande de América Latina, Nonoalco-Tlatelojco, por considerarlo una solución ante los problemas urbanos de la zona. Agrega un mapa en el que localiza las casas propias de los "intelectuales" y de los "pobres", señalando las principales zonas y colonias. En sus conclusiones observa: 1) el crecimiento primero lento y recientemente mucho más rápido de la ciudad de México; 2) el cambio en la configuración básica de la estructura en torno a la plaza central correspondiente a las antiguas ciudades mexicanas, con ciertas características similares a las zonas urbanizadas angloamericanas, incluyendo una zona de transición, y 3) ciertas diferencias entre la ciudad de México y las zonas metropolitanas angloamericanas, que van desde la ausencia de "zonas de hombres sin hogar" y "zonas residenciales de mejor clase" con "familias matricéntricas", a la forma de barrios bajos en la periferia y su tendencia a ser un centro político, comercial y cultural. Para el autor estas diferencias estructurales "reflejan aspectos distintivos de la familia moderna latinoamericana y de la vida de la comunidad de casi todos los centros urbanos de los países latinoamericanos".

Esta rápida revisión bibliográfica permite afirmar que la Escuela de Chicago ha ofrecido a la Revista Mexicana de Sociologia aportaciones de sus más destacados miembros. Durante más de 20 años es posible advertir la influencia de esta corriente de análisis del fenómeno urbano que ha desatado fuertes polémicas a partir de las cuales la sociología urbana redefinió su objeto de análisis e incorporó otras herramientas teóricas. Precisamente uno de los últimos artículos que debemos incluir en esta línea de estudio es un trabajo dedicado a analizar los conceptos de "Ciudad y política, en la sociología de Max Weber", de Roberto Agramonte (número 3 de 1965), en el cual se presenta un interesante análisis de la influencia de George Simmel sobre Park. La "mentalidad" del ente citadino es presentada como una de sus preocupaciones centrales de las condiciones psicológicas que crea la metrópoli. Se trata de la creación de la "impersonalidad citadina" que será estudiada por Wirth Louis en sus desarrollos sobrc el modo de vida que se forja la urbe (1938). También expone en su análisis la influencia de Spengler y la ya mencionada preocupación de Park por analizar una estructura societal como un estado del espíritu.

El autor busca la influencia de Weber en esta escuela, pero no como suelen hacerlo otros autores desde la perspectiva metodológica de construcción de tipos ideales, sino a partir de la formulación histórica del concepto de ciudad. Por ello recuerda que para Weber la ciudad es territorio de establecimiento de: 1) una fortificación: 2) un mercado; 3) una corte de la justicia propia, y 4) una forma de asociación regida por una ley autónoma. Weber ofreció una metodología de análisis histórico de la ciudad poco recuperada por el estructural funcionalismo preocupado mucho más por el estudio de la función de la ciudad como mecanismo 
integrador. Las tipologías de las ciudades se basan en la época y también, actualmente, mucho más en la elaboración de correlaciones estadísticas, a partir de datos censales, lo cual impone grandes limitaciones al análisis de la realidad social que los sociólogos urbanos no han sabido superar.

\section{URBANIZACIÓN Y MARgINALIDAD}

A finales de los años cincuenta puede advertirse un creciente interés por los temas tratados por la sociología urbana. Es el momento en que los mayores y mejores esfuerzos de los científicos sociales latinoamericanos se concentran en conocer la naturaleza y los efectos del proceso de urbanización, en sus vinculaciones con un proceso de desarrollo económico (esperadamente) autosostenido. Los estudios urbanos adquieren en el contexto latinoamericano una importancia social tal vez similar a la que se les otorgó en Chicago de los años veinte. Su principal función es ofrecer aportes para la formulación de políticas sociales capaces de mitigar los efectos negativos que provoca un intenso proceso de urbanización, anterior, según los observadores, a los procesos de desarrollo (industrial) localizados en las grandes metrópolis. Los problemas urbanos, el ritmo e intensidad de las migraciones rural-urbana, los marcados déficit de vivienda y equipamientos, el surgimiento de organizaciones sociales, la presencia de instituciones de carácter asistencialista y religioso en los barrios populares reorientan los estudios urbanos.

La Revista Mexicana de Sociología dedica en esos años un número especial a publicar los resultados y alcances de la primera reunión del Subcomité de Sociología Rural y Urbana de la Asociación Internacional de Sociología de la unEsco, realizada en Estambul, Turquía, cuyo objetivo fue agrupar a los estudiosos de la problemática ciudad-campo. Destacados intelectuales componían el comité, entre los cuales se encontraba el doctor Lucio Mendieta y Núñez, director del insunam en la época; Ruth Glass, de la Universidad de Londres; R. Lukié, de la Universidad de Belgrado; A. Tapia Moore, de la Universidad de Chile; Chombart de Lowe, del grupo de etnología social de París, y Kingsley Davis, del Departamento de Investigación Urbana Internacional de la Universidad de Berkely, entre otros. En una nota elaborada por Óscar Uribe Villegas sobre dicha reunión se advierte claramente las principales preocupaciones que compartían estos intelectuales. En México, como resultado del VIII Congreso Nacional de Sociología se habían realizado esfuerzos por conceptualizar en qué grado la urbanización se produce con o sin desorganización social. Óscar Lewis, Víctor-Alba, Yolanda Ortiz, Manuel Gamio y Miguel León Portilla son estudiosos dedicados a esta cuestión. Los conceptos en voga en la época son los de sobreurbanización, urbanización difusa, en proceso, artificial y desurbanización.

EI doctor Lucio Mendieta y Núnez publica una reflexión sobre los 
métodos de investigación social y la política científica del Subcomité de Sociología Rural y Urbana de la ISA, destacando especialmente el hecho de que los congresos tenían un aspecto negativo al ofrecer trabajos de carácter teórico especulativo, y que en adelante debía perseguirse como máxima: "más investigación y menos especulación", o mejor aún, "conceder preferencia a las especulaciones basadas en investigaciones sobre las especulaciones puras y las investigaciones sin teoría" (número 3 de 1958).

Dos estudiosos de los problemas urbanos ejercen una gran influencia en aquellos años, representando escuelas de pensamiento y formas de análisis de los problemas urbanos muy diferentes. Uno de ellos es Kingsley Davis, preocupado por medir cuantitativamente los procesos de urbanización. El otro, Chombart de Lauwe, representante de la sociología urbana francesa, se interesa por la ciudad como complejo social y cultural. Las contribuciones de ambos son relevantes en el marco de la investigación urbana. Gibbs y Davis (número 1958) son autores de un trabajo sobre los datos utilizables en un estudio internacional sobre urbanización en el que se presentan las dificultades de utilizar la información cuantitativa disponible por los problemas de comparabilidad que tienen las mismas.

En contrapartida, la ponencia de Chombart de Lauwe constituye un llamado a estudiar la ciudad en su unidad, advirtiendo los peligros que encierra el que los geógrafos, economistas, sociólogos e historiadores aborden aspectos parciales. Luego de presentar una reseña sobre los estudios históricos de la ciudad, asegura que son éstos los problemas básicos de la sociología urbana y que es un grave error reducir el estudio de la ciudad a un problema de funciones. Para él son las formas generales de la ciudad, sus estructuras, los temas que hay que estudiar en primer término. "La ciudad tal y como se nos presenta, es la expresión de todos los grupos, de todas las capas de la población, de todas las categorías sociales". La transformación de las estructuras encuentran en la ciudad un espacio privilegiado para acrecentar la libertad de las personas en la vida social, pero también pueden ser un medio que haga imposible toda libertad. Para Chombart de Lauwe es importante estudiar las transformaciones de las ciudades buscando la relación entre los imperativos culturales y los económicos. Entonces ofrece un "plan de estudio dinámico" de las estructuras y los comportamientos en el que se advierte la influencia de la ecología humana junto con elementos de corte funcionalista, demográficos y culturales.

Ésta es la época en que las preocupaciones sobre las relaciones campociudad atraen la atención de los científicos sociales en general y de los urbanistas en particular. Preocupaciones que perduran más de una década, porque las modalidades del desarrollo capitalista adoptado presentan crudamente sus efectos negativos sobre el espacio. Los trabajos de Jean Casimir y Bertha Lerner (número 1 de 1969), Astolfo Tapia 
(número 3 de 1958), Paul Singer (número 2 de 1978), José de Souza Martins (número 2 de 1973), Sergio Ramos (número 3 de 1970) y Raúl Benítez Zenteno (número 3 de 1962) están dentro de esta corriente. El concepto de urbanización, para este último autor, alude a la proporción de población total que vive en ciudades y zonas urbanizadas dentro de una determinada unidad, concepto adoptado en los estudios por la uNESCO. Lo importante es medir el grado de urbanización de un país, con independencia del tipo de unidades que posea. Se trata de ofrecer elementos sociológicos a la comprensión de fenómenos que tradicionalmente fueron estudiados desde una perspectiva demográfica.

Hay otro tema relacionado con los procesos de urbanización que acapara la atención de los estudiosos de la cuestión urbana: la formación y condiciones de vida que soportan grandes contingentes de trabajadores, provenientes en su mayoría del medio rural, para insertarse en el medio urbano. Las favelas, villas miserias, colonias populares, ranchos, campamentos y poblaciones son las denominaciones que reciben en distintos países latinoamericanos las formas habitacionales precarias (Brasil, Argentina, México, Venezuela, Chile). Pero en aquellos años y en estos países la sociología urbana en cierta medida se asimila con la sociología de la dependencia, desarrollada por Fernando H. Cardoso, Enzo Faletto y Teotonio Dos Santos. El proceso de urbanización latinoamericano presentaba como uno de sus rasgos más distintivos la marginalidad económica, social y territorial de gran parte de la mano de obra. Los trabajos de Aníbal Quijano y Paul Singer introducen polémicamente una nueva conceptualización y una nueva forma de explicar los procesos de urbanización latinoamericana. Más tarde, en continuidad con estos esfuerzos, Manuel Castells aporta también ideas sustantivas sobre la cuestión, incorporándose a la polémica.

En el número 3 de 1961, la Revista Mexicana de Sociología publica el original trabajo de Aníbal Quijano "La urbanización de la sociedad en Latinoamérica", y siete años después (número 3 de 1968) en otro trabajo, el mismo autor profundiza aquellas ideas en su artículo titulado "Dependencia, cambio social y urbanización en Latinoamérica". El aporte de Quijano es fundamental para repensar las causas y efectos de los procesos de urbanización en América Latina. Este autor, en su primer trabajo coloca en cuestión el punto de partida metodológico que ha prevalecido en las investigaciones al sostener que sobreviven tres problemas básicos no abordados suficientemente: 1] el relacionado con la "multidimensionalidad del proceso (lo demográfico, lo económico, lo socio-cultural); 2] la incapacidad de trascender en el análisis de la urbanización el predominio de la interpretación demográfica para identificar localidades urbanas, y 3] la caracterización de un "modo de vida" urbano. Quijano advierte que la "investigación no puede sobrepasar el nivel analítico, no puede cons. truir el lugar efectivo del proceso específico dentro del proceso general de cambio social y, así, no puede pretender sino alusivamente a establecer 
un sistema de explicación y de interpretación del significado histórico del proceso en una sociedad... Es decir, la urbanización resulta un proceso que ocurre en la sociedad, más bien que un proceso de la sociedad".

Esta forma de considerar la urbanización se desentiende de las formas tradicionales de la sociología urbana (de corte funcionalista) y se inscribe en la sociología de la dependencia, que busca en el materialismo histórico las principales herramientas para el análisis de la sociedad global. Quijano realiza la laboriosa tarea de pensar el papel que le cabe a la urbanización en proceso de cambio social, ya que no se trata de un proceso particular, separado y distinto (aunque independiente) de los procesos económico-sociales, culturales, políticos y ecológico-demográfico. "Es una dimensión del proceso global de cambio de una sociedad, el cual se expresa a través de los procesos que tienen lugar en cada uno de los respectivos órdenes estructurales en que analíticamente puede descomponerse la sociedad global". A partir de esta consideración, Quijano identifica la urbanización como una dimensión de la estructura económica, social, ecológica-demográfica, cultural psicológico-social y política. Su trabajo es una contribución a la sociología de la dependencia que pretende interpretar los procesos del cambio social en los países latinoamericanos a excepción de Cuba, protagonista de una reciente revolución socialista.

Ciertamente, la preocupación que subyace en este autor es construir el escenario de los cambios que presentan los diferentes países, los cuales transitaban a finales de los cincuenta y principios de los sesenta hacia el logro de un desarrollo autónomo en el marco de un proceso económico en el que el capital extranjero y la monopolización de la economía restringían la viabilidad de tal proyecto. Argentina, Chile y Brasil serán los países de mayor desarrollo económico en los que se frustran estos intentos de lograr esa transición económica con regímenes políticos democráticos. La imposición de gobiernos militares, la penetración del capital extranjero en esferas fundamentales de la economía nacional, su asociación con las clases dominantes nativas y la exclusión económica y política de los sectores populares constituyen los proyectos triunfantes en el contexto latinoamericano desde mediados de los años sesenta. Paul Singer trata de proponer una visión alternativa a la de Quijano. No es precisamente el carácter dependiente del proceso sino las propias modalidades del desarrollo capitalista de nuestros países las causas que generan esos procesos de urbanización periféricos y paupérrimos. Más precisamente, nuestras economías generan abundante y barata mano de obra que no logra insertarse plenamente en el aparato productivo y que debe soportar miserables condiciones de vida en el medio urbano. Es aquí donde la preocupación por la urbanización se articula a la teoría de la marginalidad, concepto que habiendo surgido muchas décadas atrás en el marco de la sociología estadunidense se reinserta ahora en un marco teórico marxista. 
En este sentido cabe hacer una apreciación de tipo metodológico. A la par que los científicos sociales latinoamericanos construyen nuevas formas de interpretación de la realidad social a partir de la utilización de las principales categorías del análisis marxista, el pensamiento funcionalista continúa dedicado a la producción de datos sobre la realidad que intenta interpretar. Pero a unos y otros científicos sociales les preocupaba conocer el comportamiento - principalmente político- que asumirán estos contingentes de trabajadores urbanos, en su gran mayoría provenientes del medio rural, sin calificación educacional y experiencia industrial, pero con una masiva presencia en esos momentos de profundos cambios sociales, económicos y políticos.

Germani ya había ensayado una interpretación particular para el caso argentino en sus explicaciones sobre la base social que llevó al peronismo al poder. La Revista Mexicana de Sociología publica un análisis muy. sugerente de este autor sobre "La ciudad como mecanismo integrador" (número 3 de 1967). Algunos trabajos que desde el funcionalismo discutían las primeras concepciones del "hombre marginal", elaborados por Park en 1928, también fueron publicados en nuestra Revista.

Alfred McClung Lee (1954), por ejemplo, recuerda los rasgos de aquel tipo ideal construido a partir de la identificación de un sujeto al margen de diferentes culturas. Con ello ciertamente se pretendía identificar conductas delictivas, ofrecer una tipología de las mismas e indicar las posibilidades de análisis que encierra la teoría de la marginalidad "especialmente para los criminólogos".

Con esta carga negativa implícita, el concepto de marginalidad es retomado en los sesenta para explicar la presencia de grandes contingentes de trabajadores urbanos no integrados plenamente a la sociedad moderna. México precisamente fue una realidad rural y urbana estudiada antropológicamente por Oscar Lewis. Como recuerda Fausto Rodríguez García (número 1 de 1961), México fue también escenario de la discusión entre ese autor y Redfield sobre la validez de identificar un tipo ideal, el folkurban continuum, la desorganización, la secularización y el individualismo, como rasgos crecientes y característicos de la influencia urbana en espacios tradicionales. Germani (número 3 de 1967), en cambio, está preocupado por evaluar concretamente los efectos políticos que desencadenan los procesos de modernización y desarrollo económico sobre la población urbana. Es en ese sentido en el que su trabajo constituye un aporte a la sociología urbana, con muchos elementos propios de una sociología del cambio social.

Las ideas centrales del trabajo de Germani (número 1 de 1967) y de Jorge Giusti (número 1 de 1968) sobre marginalidad pueden considerarse como parte de un marco teórico funcionalista, que prácticamente desaparece del análisis sociológico de la cuestión urbana en la siguiente década. Germani decía: "El papel de la ciudad como mecanismo integrador incluye la consideración de dos aspectos diferentes: a] la integración geo. 
gráfica de la sociedad nacional, que puede ser definida como el proceso 'balanceado' o equilibrado de modernización y desarrollo económico de sus regiones, componentes y su participación igual o proporcional en la vida económica, cultural y política de la nación, y b] la integración social, es decir, la integración. La ciudad 'primera' con su gran concentración de riqueza...". Germani está particularmente interesado en el segundo aspecto, la integración social, al que vincula nociones tales como participación, movilización y marginalidad; para este último concepto reserva una visión ecológica y psicosocial. $\mathrm{El}$ autor advierte que la principal preocupación de la Escuela de Chicago es la "desintegración", más que la "integración". Los aspectos anímicos de la vida urbana, la idealización mítica de la comunidad del pasado, la construcción de una visión antiurbana frente a la cual Latinoamérica ofreció un buen material para esa crítica (Lewis, en México, fue uno de los principales aportes). La ciudad para Germani proporciona importantes mecanismos de movilización que se contraponen a la desorganización: concretamente la educación y los medios de comunicación. En los países en desarrollo existe una sobreurbanización que "significa que la movilización objetiva (especialmente la migración del campo a las ciudades) y la movilización psicosocial (a través de mayor contacto con los medios de comunicación) tienden a preceder el desarrollo económico más que a seguirlo - como ocurrió con más frecuencia en el pasado". Aquí se advierte en Germani una interpretación de los procesos de urbanización latinoamericanos claramente opuesta a la ofrecida por los sociólogos de formación marxista. La concepción gradual, de cambio social, la creencia en una sucesión de etapas de desarrollo económico, el concepto de transformación de las estructuras hacia su modernidad, son ideas que se construyen a partir de la confrontación con los patrones presentados por los países centrales.

$\mathrm{El}$ trabajo concluye precisamente al retomar la preocupación por la marginalidad social, ante una realidad rebelde que muestra al observador que puede existir incluso crecimiento económico, pero que lo ineludible son los elevados niveles de pobreza. $\mathrm{Y}$ esta población posee una potencialidad política cuyos alcances intenta medir cuando sostiene: "El sector marginal urbano puede, políticamente, ser no-participante durante mucho tiempo; o su movilización política y su integración a movimientos integrados pueden ocurrir a través de su absorción en papeles ocupacionales más modernos. Como lo muestran algunos estudios realizados en Brasil y en otras partes, aun en tal caso, la politización probablemente tendrá lugar a través de diferentes etapas y esto dependerá considerablemente del grado de modernización de su lugar de origen. Asimismo, en circunstancias particulares, la participación política puede tener lugar sin cambios ocupacionales. El sector marginal urbano puede hacerse políticamente importante sin perder marginalidad cultural y económica, y esto puede ser consecuencia muy importante de la urbanización".

En realidad las formas de organización social y política que habían 
desarrollado ya los pobladores de las favelas, villas miserias, las poblaciones, en fin, ese universo "marginal", indicaban que para entonces se había constituido una base social que partidos políticos y diferentes organizaciones de la sociedad civil (asistencialistas, religiosas) y gubernamentales intentaban disputar como clientela de su acción. No debe olvidarse que es la época en que en diferentes países del área se forman organizaciones políticas que reclaman profundos cambios en la estructura social, y este sector de la población constituye un actor social alternativo al considerado tradicionalmente como principal agente portador del cambio social: la clase obrera.

El trabajo de Jorge Giusti, "Rasgos organizativos en el poblador marginal urbano latinoamericano" (número 1 de 1968), forma parte de este pensamiento sociológico, que influido marcadamente por el propio Germani busca los referentes históricos del comportamiento político del "hombre marginal". La cuestión fundamental es analizar al poblador marginal chileno en relación con el tipo de vivienda precaria que habita (poblaciones, callampas, conventillos, barrios que son producto de erradicaciones) con las formas organizativas que desarrolla. Los resultados de la política asistencialista desarrollada en Chile por la Democracia Cristiana significaban no sólo tolerancia política hacia su existencia, sino también suministrar servicios y mejoras en las condiciones de vida. Chile en aquellos años constituía un espacio de estudio privilegiado para abordar esta temática y la dimensión política de los problemas urbanos ganó creciente centralidad. Como veremos en seguida, la sociología urbana de los setenta abandona definitivamente los interrogantes principales del funcionalismo (organización / desorganización, integración / desintegración, modernidad / atraso) y se ubica en una perspectiva crítica que apoyada en diferentes vertientes del materialismo histórico ofrece nuevas bases teóricas para el análisis de los fenómenos urbanos. Irving L. Horowitz (número 1 de 1966) en su artículo "La política urbana en Latinoamérica" apuntaba a resolver problemas bastantes cercanos a los señalados por Germani. En realidad, su trabajo no es un análisis de la política urbana - no en el sentido de formas de intervención estatal sobre espacio urbano- sino más bien un conjunto de reflexiones sobre la política, sobre el juego político en el medio urbano (mecanismos de cooptación, comportamiento de élites locales, efectos sociales de las migraciones campo-ciudad, cultura política de diferentes grupos sociales). Horowitz, en síntesis, comparte la idea de que las ciudades latinoamericanas son laboratorios para el examen y el análisis de las clases sociales emergentes, para explotar los efectos de la industrialización y para los estudios sobre el cambio social basado, según él, en la reforma, "y si esto falla lo serán para un cambio basado en la revolución social", sostiene Horowitz.

Es interesante revisar estos artículos porque si bien preceden cronológicamente a la temática de los movimientos sociales urbanos, nada indica que los mismos hayan sido discutidos o incorporados polémicamente. Más 
bien, la incorporación del materialismo histórico al estudio de la problemática urbana puede ser caracterizada como una ruptura teórico-metodológica en este campo del conocimiento.

Pero la marginalidad urbana en América Latina es un tema que perdura y continúa acaparando la atención de autores cuya producción puede inscribirse en distintos cuerpos teóricos. En las décadas siguientes la $R \boldsymbol{e}$ vista Mexicana de Sociología dedica tres números a la cuestión (números 4 de 1977, 1 de 1978 y 4 de 1981). Los artículos contenidos en estos números son de dos tipos. Por un lado, aquellos que recurren nuevamente a la revisión teórica del concepto y su confrontación con los resultados de investigaciones, tratando de hacer un balance crítico sobre el estado del conocimiento del tema (Alain Touraine, número 4 de 1977; Vilmar Faria, número 1 de 1978; Antonio Murga, número 1 de 1978; Veronika Benholdt-Thomsen, número 4 de 1981;; Silvia Sigal, número 4 de 1981; Rubén Oliven, número 4 de 1981). Por otro, un conjunto de trabajos que se apoyan en este concepto para analizar situaciones concretas relacionadas con el comportamiento y modalidades del mercado de trabajo en distintos países del área o con expresiones políticas de los llamados grupos marginados (Sonia de Avelar, número 4 de 1977; Luis Serrón, número de 1977; Lucio Kowarick, número 1 de 1978; José Nun, 1978; Larissa Lomnitz, número 1 de 1978; Sergio Zermeño, número 4 de 1978 y Ricardo Rodríguez Silvero, número 4 de 1981).

La importancia de la dimensión política otorgada al análisis de la cuestión urbana es creciente y será el común denominador de los trabajos que pasaremos a considerar seguidamente.

\section{Estructura urbana, movimientos sociales URbanos Y PODER LOCAL}

Desde finales de los sesenta se consolidaron en diferentes países de América Latina grupos de investigadores dedicados al estudio de los problemas urbano-regionales: el cidu en Chile, el ceur en Buenos Aires, CEBRAP en Brasil, Aníbal Quijano en Perú y diferentes investigadores en México. Este trabajo académico encuentra en la sociología francesa importantes elementos teóricos y estrategias de investigación para reorientar la investigación latinoamericana, aun cuando en menor medida se realizan trabajos en los que se incorporan elementos teóricos ofrecidos por los autores clásicos de la sociología y del funcionalismo.

La Revista Mexicana de Sociología continúa siendo un espacio para divulgar los estudios sobre el territorio, la ciudad, lo urbano contenido en el análisis de diferentes problemas sociales. En México, Enrique Contreras (número 4 de 1971) desarrolla importantes investigaciones en torno a la problemática del empleo urbano. "Inestabilidad ocupacional y estratificación urbanas" constituye una contribución al estudio de la hetero- 
geneidad ocupacional prevaleciente en los países en desarrollo. Años después, en "Movilidad y oportunidades de empleo en la Ciudad" (número 2 de 1974), este autor explora las pautas de movilidad y las oportunidades de empleo en la capital del país. Ernest Feder (número 1 de 1974) presenta un análisis sobre "la pobreza y el desempleo en América Latina", de 1957 a 1974 y otro tema fundamental para la comprensión de los principales problemas de la ciudad es el de las migraciones internas. Los estudios de Humberto Muñoz, Brígida García y Orlandina de Oliveira números 1 de 1976 y 1 de 1978, así como de Enrique Contreras (número 3 de 1975 ) presentan pormenorizados análisis sobre las migraciones internas, el mercado de trabajo urbano y la constitución de los grupos populares urbanos. Este tipo de estudios sociológicos, demográficos y antropológicos consideran la ciudad no como objeto de análisis en sí mismo, sino como un contexto territorial particular, en el cual se ponen a prueba hipótesis de trabajo sobre el comportamiento poblacional.

Los años setenta, como adelantamos, constituyen un momento de ruptura, de distanciamiento con los marcos tradicionales de análisis de la sociología urbana para dar paso a la utilización de los conceptos y categorías marxistas en la interpretación y análisis de los fenómenos urbanos. Se advierte una fuerte influencia de las ideas de Althusser y Poulantzas, y la sociología latinoamericana encuentra en Castells, Borja, Lojkine, Topalov y Harvey nuevas interpretaciones y nuevos temas de estudio. Puede decirse que la sociología urbana recupera (tal vez a pesar de estos mismos autores) un objeto de análisis definido. Considerar lo urbano como espacio de reproducción de la fuerza de trabajo es un buen punto de partida para generar nuevos interrogantes, despertar la polémica académica y transitar hacia la construcción de un marco teórico distinto. La Revista Mexicana de Sociología es un buen testimonio al publicar en español uno de los primeros escritos de Manuel Castells (número 1 de 1972). Este autor forma parte del grupo coordinado por Louis Althusser, y los investigadores de la Escuela Normal Superior de París que elabora desde el marxismo los conceptos de estructura urbana, sistema urbano y movimientos sociales urbanos. Partiendo del concepto central de modo de producción, el sistema urbano es definido como: "La articulación específica de los elementos del sistema económico dentro de una unidad de consumo colectivo"; y el movimiento social "como una organización del sistema de actores (coyuntura de las relaciones de clase) que llega a producir un efecto cualitativamente nuevo sobre la estructura social (efecto pertinente". Castells construyó un modelo en cierta medida formal para el estudio de ese sistema urbano a partir de la identificación de los momentos de la producción, el intercambio, la gestión y el consumo en el nivel de la unidad urbana. El momento del consumo, distinguible sólo analíticamente, es el momento fundamental para comprender la naturaleza de las prácticas urbanas. Castells sostiene en aquel pionero trabajo: "Se entiende por práctica urbana toda práctica social relativa a la organización 
interna de las unidades de consumo colectivo o que en vista de los problemas generales de consumo colectivo adopta como campo de acción las unidades urbanas".

Sin duda Castells es uno de los autores de mayor importancia, porque su producción académica orientó y signó la investigación urbana latinoamericana. Sus trabajos en Chile y la traducción de sus textos al español hicieron de este autor una obligada referencia para la sociología urbana. La política urbana, las acciones del Estado capaces de incidir en las formas de ocupación y uso del suelo urbano y los movimientos sociales urbanos, verdaderos agentes de cambio social con capacidad de producir efectos en la estructura urbana y en la estructura social constituyó la relación de estudio privilegiada por la investigación.

Más tarde, Castells elaboró y publicó una interpretación sobre el análisis de clase de la política urbana del Estado mexicano (número 4 de 1977), en el que trata el problema de la vivienda en un contexto de crisis y la respuesta gubernamental a las demandas populares. En él, Castells recupera los resultados de los trabajos que ya habían realizado en el país otros investigadores. Debe recordarse que desde mediados de los setenta existe en México un grupo de investigadores que en instituciones de nivel superior (la unAM, El Colegio de México y la entonces recientemente creada UAM) y en centros de investigación privados como copevi, adquieren presencia en el quehacer científico nacional y latinoamericano por sus aportaciones en el área de los estudios urbano-regionales. Actualmente existe un número relativamente grande de académicos (investigadores y docentes) insertos en un mayor número de instituciones públicas y privadas cuyos trabajos son aportes sustanciales a la comprensión de los complejos fenómenos urbanos, lo cual se refleja en un número creciente de publicaciones.

En el número 3 de 1979 Manuel Perló presenta los principales resultados de una investigación histórica: "Política y vivienda de México 1910-1952". En este trabajo Perló realiza una revisión exhaustiva de la acción estatal en materia de vivienda desde el período revolucionario hasta el alemanismo. El autor concluye que hasta el advenimiento de Cárdenas el núcleo de las contradicciones habitacionales que afectan a las clases trabajadoras urbanas se localiza en el sistema de vivienda arrendado del centro de las ciudades. Pero también, aunque tiene una importancia cuantitativa limitada hasta el gobierno de Alemán, es necesario mencionar la vivienda estatal y la ruptura que provoca a partir del cardenismo la aparición de las colonias proletarias dentro de la estructura urbana existente.

La vivienda es uno de los temas privilegiados en la investigación urbana en Latinoamérica y México, al que se agrega la política urbana y los movimientos sociales urbanos. Más recientemente se incorporan la descentralización y el poder local como temas ineludibles en un contexto latinoamericano en que la principal preocupación es la consolidación y 
profundización de la democracia. En 1981 la Revista presenta un grupo de trabajos de investigadores mexicanos y latinoamericanos agrupados bajo el subtítulo de la cuestión urbana, sin duda parafraseando el importante libro de Manuel Castells (1976). Jordi Borja encabeza estos trabajos presentando un ensayo titulado "Movimientos urbanos y cambio político" (número 4 de 1981). En su introducción, el autor se encarga de desmitificar la naturaleza y los alcances políticos de estos movimientos diciendo: "Los movimientos emergentes tienen una apariencia revolucionaria y una relativa ineficacia política que despiertan las simpatías de los espectadores”, y agrega más adelante: “... Los movimientos urbanos no pueden reducirse a su dimensión reivindicativa, ni tampoco su carácter cívico-político". Luego de analizar las relaciones que guarda su existencia con las condiciones de vida, Borja introduce un tema que será una constante en las futuras reflexiones de este autor: la cuestión de la democratización del Estado. Piénsese que estos primeros trabajos tienen como marco de referencia el franquismo español y los movimientos urbanos son sustanciales en los procesos de democratización política. Una función que el autor le atribuye a estos movimientos es la de "agregación social", de constructores o reconstructores del tejido colectivo; pero a ello agregan una capacidad fundamental: la de cumplir una función informativa e instrumental, obligando a las instituciones a modificarse, a crear interlocutores, a asumir nuevas problemáticas, a negociar y hacer concesiones. $\mathrm{Al}$ mismo tiempo "...los movimientos urbanos, una vez alcanzado cierto consenso social, amplitud y continuidad, se convierten en un medio para asegurar la participación y el control en las instituciones locales, para cambiar la legalidad, para abrir un proceso de reforma del Estado". Es precisamente este último aspecto el que Borja desarrolla de manera original mostrando la importancia de lograr una democratización de la administración local, como instituciones representativas elegidas y encargadas de la gestión urbana.

La descentralización y su contrapartida, el fortalecimiento de los poderes locales, son los principales objetos de atención (más política que académica en un sentido estricto). Ésta es realmente una de las ideas centrales que irá desarrollando en otros trabajos publicados en nuestra Revista. Poco tiempo después Borja, en su trabajo "Política municipal, la izquierda cumplió 60 años" (número 1 de 1982) ofrece un balance de la acción de la izquierda en la dirección de los ayuntamientos en Cataluña. A las contradicciones y dilemas de la política municipal Borja opone una salida positiva en el desarrollo del Estado de las autonomías. La búsqueda de una política municipal de izquierda lo lleva a señalar cuestiones nodales tales como: 1] la necesidad de pactos municipales, especialmente el acuerdo entre socialistas y comunistas, 2] solucionar la falta de recursos, 3] el saneamiento y racionalización de las empresas y servicios municipales, 4] la reforma administrativa como un aspecto central de la actividad municipal y 5] la información y participación como una 
cuestión clave de la política municipal de izquierda. Borja concluye con la propuesta de que al desarrollo del Estado de las autonomías y la realización de reuniones estatales de alcaldes y de municipios debe agregarse el proyecto de federación de municipios. La propia vida política de Borja, su cargo de teniente de alcalde en el Ayuntamiento de Barcelona y actual concejal, le ha permitido poner a prueba muchas de estas ideas; pero lo fundamental es que su presencia en América Latina ha contribuido a incorporar nuevas líneas de investigación, una de las cuales es sin duda la cuestión del poder local.

En el marco del Proyecto de Cooperación para la Democracia Local en América Latina que coordinan el Instituto de Cooperación Iberoamericana y clacso, la Revista Mexicana de Sociología publica en el número 4 de 1986 un conjunto de investigaciones sobre poder local. Estos trabajos comparten una preocupación común por el análisis de los gobiernos locales tanto desde la perspectiva de la sociedad global como desde la de algunos elementos que han sido ya estudiados por la investigación urbana, como es el caso de los movimientos sociales urbanos en el ámbito municipal. Carlos Martínez Assad y Alicia Ziccardi intentan acercarse a un diagnóstico sobre esa heterogénea y compleja unidad de análisis que es el municipio mexicano, ofrecen elementos para la construcción de una tipología municipal, abordan los alcances de la reciente reforma municipal y presentan un mapa de la política electoral. El caso chileno, presentado por el equipo del Sur integrado por Vicente Espinoza, Alfredo Rodríguez y Alex Rosenfeld muestra crudamente la incongruencia de una de las hipótesis fundamentales de las que parten nuestras investigaciones: "la descentralización en el caso chileno no es consustancial a la democracia". Muy por el contrario, es parte de un articulado proyecto de modernizar las formas de control social ejercido férreamente por la dictadura militar instalada en aquel país. Fernando Kusnetzoff (número 1 de 1983) había presentado años antes en la Revista Mexicana de Sociología un interesante análisis sobre el gobierno local y una audaz comparación tomando la experiencia chilena y la nicaragüense.

Este tema del poder local encuentra en los casos de Bolivia, estudiado por Alberto Rivera; de Quito, por Fernando Carrión; de Argentina, por Pedro Pirez; de Brasil, por Edson Núñez; de Colombia, por Fernando Viviesca, y de Venezuela, por Giulette Fadda una gran variedad de nuevos interrogantes en torno a las posibilidades económicas, políticas y sociales que tiene cada contexto nacional analizado. También desde una perspectiva teórica Susana Peñalva busca con éxito las articulaciones existentes entre espacio urbano y sociedad en el marco de la crisis actual latinoamericana.

La Revista ofrece un rico material para confrontar cada una de las experiencias latinoamericanas con las "Transformaciones territoriales e institucionales en Europa", título del artículo que Jordi Borja ofrece en el número 4 de 1986 y en el que reseña los más importantes cambios 
regionales e institucionales que se dieron en Gran Bretaña, Francia, Italia, Alemania, Austria, Suiza, Bélgica, Dinamarca, Suecia y los tres países mediterráneos que en los años setenta pasan de la dictadura a la democracia: Portugal, Grecia y España. Aquí Borja traspasa su preocupación por los territorios metropolitanos a otras realidades (municipios y regiones) repensando las características que adquiere la administración y el urbanismo en la sociedad poscrisis. Finalmente recurre a las cuestiones del método abordando los problemas que enfrenta un proceso de descentralización a nivel de los aparatos del Estado involucrados, sus objetivos y los efectos sobre el territorio y sobre la administración. Este es precisamente un tema central que en el número 4 de 1984 Borja desarrolla en otro artículo: "Descentralización: una cuestión de método".

Pero en los ochenta, como dijimos, se otorga aún mucha importancia al tema de los movimientos sociales urbanos y de los componentes de la estructura urbana. Una rápida revisión indica que se dedican muchos esfuerzos a estudiar las formas de producción del espacio en México y en otros países de América Latina. Guillermo Boils (1981) analiza 20 años de revolución cubana, tema tratado también por Joseph Gugler (número 4 de 1981); Samuel Jaramillo y Martha Schteingart (número 1 de 1983) ofrecen un análisis sobre "Procesos sociales y producción de vivienda en América Latina: 1960-1980", a partir de los casos de Colombia y México; Vilmar Farías se ocupa del sistema urbano en Brasil (1981) ; Beatriz García Peralta (número 4 de 1981) presenta los resultados de una investigación sobre la presencia del Estado y del capital privado en un fraccionamiento en la periferia de la ciudad de México. El transporte y los medios de circulación material son temas nuevos tratados, en el caso de México, en los trabajos de Bernardo Navarro (número 4 de 1984) y también Carolina Grajales y Felipe Lara (número 3 de 1983). El abasto tema investigado por Héctor Castillo (número 3 de 1983) pasa a formar parte también de las preocupaciones urbanas en México. Pero en el marco de la grave crisis económica y de los proyectos de profundización de la democracia del actual sistema político, el tema de los movimientos sociales urbanos aún conserva y hasta acrecienta su importancia. Castells fue pionero en este tema con su artículo "Proporciones teóricas para el estudio de los movimientos sociales urbanos" (número 1 de 1972).

La traducción de los trabajos de Tilman Evers (números 4 de 1981 y 4 de 1982) sobre movimientos barriales y sobre el costo de la vida en Brasil permite conocer un análisis desde una perspectiva teórica original sobre la relación movimientos sociales-Estado. Un polémico trabajo de Luis Alvarado (1981), "Notas sobre las perspectivas teóricas en el análisis de las luchas reivindicativas urbanas" ofrece una particular interpretación sobre los enfoques prevalecientes (ecologistas, culturalistas, catastrofistas, ordenadores, clasistas en la terminología del autor). Como ya se mencionó, Borja (1981) contribuyó a aportarnos una interpretación 
original a la potencialidad política de estos movimientos. Lo relevante de estos artículos es el haber ofrecido a los estudiosos de la cuestión y a quienes toman decisiones políticas un conjunto de ideas sobre el papel social de los movimientos urbanos. En los mismos se consideran, a partir de diferentes contextos nacionales, las formas de organización y lucha que protagonizan las clases populares en demanda de bienes y servicios urbanos. La tierra, la vivienda, el transporte y los servicios habitacionales son el conjunto de reivindicaciones a partir de las cuales se constituyen organizaciones sociales de corte reivindicativo y político. Al caso de México estudiado por Fernando Bejarano (número 3 de 1983), Manucl Perló y Martha Schteingart (número 4 de 1984) y Sergio Zermeño (1987) se agregan las contrastantes experiencias de Brasil investigadas por José A. Moisés (número 4 de 1978), Pedro Jacobi (1984), Luis A. Machado y Paulo Magalaes (número 4 de 1984) y Lucio Kowarick (número 4 de 1984), de Colombia tratado por Gilma Mosquera (número 4 de 1984) y de Argentina, estudiado por Alicia Ziccardi (números 1 de 1983 y 4 de 1984). En la introducción al número de la Revista Mexicana de Sociología dedicado a analizar estos temas urbanos se sostiene: "La crisis mundial del capitalismo se ha encargado de generar un nuevo escenario para el estudio de los problemas urbanos. Con mayor o menor intensidad, el denominador común de nuestras sociedades es el deterioro sistemático de la calidad de vida, el cual responde a un conjunto complejo de factores económicos; políticos y sociales, propios de cada realidad nacional. Pero si bien la crisis ha permeado todos los ámbitos de la sociedad, también ha engendrado en su interior proyectos y formas de organización de las clases populares en defensa de sus niveles de consumo". Los trabajos publicados en la Revista Mexicana de Sociología en esos años son testimonio de ello.

Tal vez sea interesante contrastar estas preocupaciones que prevalecen en el contexto latinoamericano con las del urbanismo de los países centrales. El trabajo de Castells "La crisis, la planificación y la calidad de vida: el manejo de las nuevas relaciones históricas entre espacio y sociedad" puede ser un buen punto de partida. El mismo Castells amplía enormemente su marco de análisis instalando su trabajo en el contexto de la crisis del capitalismo y en la revolución de la informática. Su preocupación ahora no son precisamente las clases sociales que constituyen los movimientos urbanos sino las categorías sociales que crecientemente los protagonizan (las mujeres, los grupos ecologistas, etc.). El impacto de las nuevas tecnologías sobre las formas de organización del espacio constituye para el autor otro dato de una nueva realidad económica y social que modifica sustancialmente el horizonte de los comportamientos colectivos y las formas de ocupación del espacio (número 4 de 1984).

Finalmente, la dura realidad mexicana generada en 1985 por el terremoto que azotó la ciudad de México obligó a que los cientistas sociales of reciesen elementos para lograr propuestas inmediatas que atendiesen las demandas de la población damnificada. La Revista testimonia los 
primeros análisis sobre la población damnificada a partir de la encuesta realizada por un amplio conjunto de investigadores y coordinada por el área de sociología de la población del insunam (Cecilia Rabell y Martha Mier y Terán, Julieta Quilodrán, Teresita de Barbieri y Carlota Guzmán). (todos en el número 2 de 1986) aportan también un conjunto de trabajos sobre los efectos del desastre. Organizando y sistematizando información sustancial para elaborar propuestas y programas de atención a los damnificados se publican también los artículos de Álvaro Arreola, José Georgette, Matilde Luna, Ricardo Tirado, Alicia Ziccardi, A. Massolo, Guillermo Boils, Margarita Camarena, Beatriz García (todos en el número 2 de 1986).

\section{BIBLIOGRAFIA}

Azuela, Antonio y Duhay, Emilio, "De la economía política de la urbanización a la sociología de las políticas urbanas", en Sociológica, año 2, núm. 4, México, 1987, pp. 41-69.

Bettin Gianfranco, Los sociólogos de la ciudad, Gustavo Gilli, Barcelona, 1982.

Castells, Manuel, Problemas de investigación en Sociología Urbana, Siglo XXI, México, 1976.

Castells, Manuel, La cuestión urbana, Siglo XXI, $2^{n}$ edición, México, 1976.

Cheetham Rosemond, "Estado del conocimiento sobre el fenómeno metropolitano", en Revista A UAM, vol. 5, núm. 11, enero-abril, México, 1984, pp. 169-195.

Donoso, Roberto, "Algunas reflexiones sobre la sociología urbana", en Revista Mexicana de Ciencias Políticas y Sociales, año XXXIII, Nueva Época, abril-junio, núm. 128, UNAM, México, 1987, pp. 9-26.

Ledrut, Raymond, Sociología urbana, Instituto de Estudios de Administración Local, Madrid, 1976.

Preteceille, Edmond, "Políticas Urbanas e Servicos Coletivos: Um Belanço dạs Pesquisas", en Espaço e Debates, año 6, São Paulo, 1986, pp. 5-18.

Remy, Jean y Voye, Liliane, La ciudad y la urbanización, Instituto de Estudios de Administración Local, Madrid, 1976.

Ziccardi, Alicia y Saltalamacchia, Homero, "Estado y política urbana: una revisión bibliográfica", en Iztapalapa, año 2, núm. 3, julio-diciembre, México, 1980, pp. 306-316.

Alicia Ziccardi, "Reflexiones sobre la investigación urbana y el poder local", en González Casanova, Pablo y Martínez Assad, Carlos, Balance y Perspectivas de los Estudios Regionales, Siglo XXI, en prensa. 


\section{Ecologia urbana y comunidad}

Agramonte, Roberto, Ciudad y política en la sociología de Max Weber, vol. 27, núm. 3, sep-dic., 1965, pp. 803-839.

Dotson, Floyd y Lillian Ota Dotson, La estructura ecológica de las ciudades mexicanas, vol. 19, núm. 1, ene.-abr., 1957, pp. 39-66.

Germani, Gino, El estudio integral de las comunidades, vol. 12, núm. 3, sept.-dic., 1950, pp. 307-332.

Hayner, Norman S.. La ciudad de México: su estructura ecológica latino. americana, vol. 26, núm 1, ene.-abr., 1964, pp. 221-231.

I.ee, Alfred Mcclung, Reconsideración sobre la teoría de Park sobre la marginalidad, vol. 16, núm. 3, sept-dic., 1954, pp. 375-386.

Mowrer, Ernest R., El estudio ecológico de la ciudad, vol. 5, núm. 1, ene.-mar., 1943, pp. 19-25.

Queen, Stuart A.. Sociología de la ciudad, vol. 6, núm. 3, sept.-dic., 1944. pp. 371-380.

Redfield, Robert, La sociedad folk, vol. 4, núm. 4, oct.-dic., 1942, pp. 13-41.

Rodríguez García, Fausto, Reflexiones sobre las obras de Redfield y Lewis acerca de Tepoztlán, México, vol. 23, núm. 1, ene.-abr., 1961, pp. 133-145.

Romero, Francisco, Sobre los rasgos distintivos de la sociedad humana, vol. 14, núm. 3, sept.-dic., 1952, pp. 453-457.

\section{Urbanización y marginalidad}

Agulla, Juan Carlos, Aspectos sociales del proceso de industrialización en una comunidad urbana, vol. 25, núm. 2, may.-ago., 1963, pp. 747-772.

Benítez Zenteno, Raúl, La población rural y urbana de México, vol. 24, núm. 3, sept.-dic., 1962, pp. 689-703.

Bennholdt-Thomsen, Veronika, Marginalidad en América Latina. Una critica de la teoria, vol. 43, núm. 4, oct.-dic., 1981, pp. 1505-1546.

Canchola, Antonio, Relaciones sociales y económicas de la ciudad y el campo en México, vol. 19, núm. 1, ero.-abr., 1957, pp. 15-23.

Casimir, Jean, Definición y funciones de la ciudad en América Latina, vol. 32, núm. 6, nov.-dic., 1970, pp. 1497-1511.

Casimir, Jean, Definición y funciones de la ciudad en América Latina, vol. 35, núm. 2, abr.-jun., 1973, pp. 399-412.

Casimir, Jean y Bertha Lerner Sigal, La estructura de dominación ciudadcampo, vol. 31, núm. 1, ene.-mar., 1969, pp. 129-142.

Celal Sarc, Omer, La urbanización en Turquia, vol. 20, núm. 3, sept.dic., 1958, pp. 691-698.

Cinta, Ricardo, Desarrollo económico, urbanización y radicalismo político, vol. 31, núm. 3, jul.-sept., 1969, pp. 643-688. 
Chombart de Lauwe, Paul, Esbozo de un plan de investigaciones acerca de la vida social en el medio urbano, vol. 20, núm. 3, sept.-dic., 1958, pp. 637-648.

Ducoff, Louis J., La brecha entre el desarrollo rural y el urbano: la experiencia de México, vol. 30, núm. 2, abr.-jun., 1968, pp. 201-216.

Darkot, B., El censo del año 1955 en Turquía desde el ángulo de la urbanización, vol. 20, núm. 3, sept.-dic., 1958, pp. 687-689.

De Avelar, Sonia María, Notas teóricas y metodológicas para el estudio del trabajo industrial a domicilio en México, vol. 39, núm. 4, oct.-dic., 1977, pp. 1227-1250.

Fahri Finde Koglu, Ziyaeddin, Caracteristicas del movimiento de urbanización en Turquia, vol. 20, núm. 3, sept.-dic., 1958, pp. 699-706.

Faria Vilmar, Desarrollo económico y marginalidad urbana: Los cambios de perspectiva en la CEPAL, vol. 40, núm. 1, ene.-abr., 1978, pp. 9-29.

García, Brígida; Muñoz, Humberto y De Oliveira, Orlandina, Migraciones internas y grupos populares urbanos: ciudad de México (19501970), vol. 40, núm. 1, ene.-abr., 1978, pp. 107-129.

Germani, Gino, Urbanización, secularización y desarrollo económico, vol. 25, núm. 2, may.-ago., 1963, pp. 625-646.

Germani, Gino, La ciudad como mecanismo integrador, vol. 29, núm: 3, jul.-sept., 1967, pp. 387-406.

Gibbs, Jack P. y Davis Kingsley, Características de los datos utilizables en un estudio internacional sobre urbanización, vol. 20, núm. 3, sept.dic., 1958, pp. 649-667.

Giusti, Jorge, Rasgos organizativos en el poblador marginal urbano latinoamericano, vol. 30, núm. 1, ene.-mar., 1968, pp. 53-77.

Horowitz, Irving Louis, La política urbana en latinoamérica, vol. 28, núm. 1, ene.-mar., 1966, pp. 71-112.

Klages, Helmunt, La "vecindad" en la gran ciudad, vol. 26, núm. 3, septdic., 1964, pp. 833-850.

Kowarick, Lucio, Desarrollo capitalista y marginalidad: El caso brasileño, vol. 40, núm. 1, ene.-abr., 1978, pp. 31-54.

Labastida, Horacio, El desarrollo de la comunidad en América Latina, vol. 29, núm. 1, ene.-marz., 1967, pp. 53-68.

Lomnitz, Larissa, Mecanismos de articulación entre el sector informal y el sector formal urbano, vol. 40, núm. 1, ene.-abr., 1978, pp. 131-153.

Martínez Ríos, Jorge, La definición del elemento "folk" de folklore con base en la realidad de México, vol. 25, núm. 1, ene.-abr., 1963, pp. 235-243.

Mendieta y Núñez, Lucio, Los métodos de investigación social y la politica científica del subcomité de sociología rural y urbana de la Asociación Internacional de Sociología, vol. 20, núm. 3, sept.-dic., 1958, pp. 625-635.

Murga Franssinetti, Antonio, La marginalidad urbana en América Latina: 
una bibliografia comentada, vol. 40, núm. 1, ene.-abr., 1978, pp. 221 331.

Nun, José, La industria automotriz argentina: estudio de un caso de superpoblación flotante, vol. 40, núm. 1, ene.-abr., 1978, pp. 55-106.

Oliven, Rubén George, Aspectos económicos, políticos y culturales de la marginalidad urbana en América Latina, vol. 43, núm. 4, oct.-dic., 1981, pp. 1627-1643.

Quijano, Aníbal, La urbanización de la sociedad en Latinoamérica, vol. 29, núm. 3, oct.-dic., 1961, pp. 669-703.

Quijano, Aníbal, Dependencia, cambio social y urbanización en Latinoamérica, vol. 30, núm. 3, 1968, pp. 525-570.

Ramos Galicia, Sergio, Urbanización, cambio social y dependencia, vol. 31, núm. 1, ene.-mar., 1969, pp. 143-157.

Ramos Galicia, Sergio, El proceso de urbanización ecológico-demográfico en México 1900-1960, vol. 32, núm. 3, sept.-oct., 1970, pp. 1251-1270.

Rodríguez Silvero, Ricardo, La marginalidad estructural en Paraguay. Análisis de uno de los síntomas paradigmáticos del subdesarrollo, vol. 43, núm. 4, oct.-dic., 1981, pp. 1579-1625.

Rosenmayr, Leopold, Anotaciones sobre el fenómeno de la urbanización allende la ciudad, vol. 20, núm. 3, sept.-dic., 1958, pp. 733-742.

Serron, Luis, Escasez, explotación y pobreza en México: Conclusiones, vol. 39, núm. 4, oct.-dic., 1977, pp. 1143-1160.

Sigal, Silvia, Marginalidad espacial, estado y ciudadania, vol. 43, núm. 4, oct.-dic., 1981, pp. 1547-1577.

Singer, Paul, Campo e cidade no contexto historico Latinoamericano, vol. 35, núm. 2, abr.-jun., 1973, pp. 301-319.

Souza Martins, José de, As relaçes de troca entre o campo e a cidade, vol. 35, núm. 2, abr.-jun., 1973, pp. 321-335.

Tapia Moore, Astolfo, Diferentes condiciones de vida en la ciudad y en el campo, vol. 20, núm. 3, sept.-dic., 1958, pp. 669-677.

Touraine, Alain, La marginalidad urbana, vol. 39, núm. 4, oct.-dic., 1977, pp. 1105-1142.

Ulken, Hilmi Ziya, Algunas consecuencias del movimiento de urbanización, vol. 20, núm. 3, sept.-dic., 1958, pp. 707-711.

Uribe Villegas, Óscar, Nota acerca de la primera reunión del subcomité de Sociología Rural y Urbana de la Asociación Internacional de Sociología de la UNESCO, vol. 20, núm. 3, sept.-dic., 1958, pp. 611-623.

Talmon-Garber, Yonina, La urbanización en Israel, vol. 20, núm. 3, sept.dic., 1958, pp. 725-732.

Zermeño, Sergio, Estado, clases y masas, vol. 40, núm. 4, oct.-dic., 1978, pp. 1283-1325.

Zimmerer, Paul, Una sección central para la región urbana, vol. 20, núm. 2, may.-ago., 1958, pp. 578-579. 
III. Estructura urbana, movimientos sociales urbanos y poder local.

Alvarado C., Luis, Notas sobre las perspectivas teóricas en el análisis de las luchas reivindicativas urbanas, vol. 43, núm. 4, oct.-dic., 1981, pp. 1345-1413.

Arreola Ålvaro; Georgette José V.; Matilde Luna y Ricardo Tirado, Memoria: los primeros ocho días, vol. 48, núm. 2, abr.-jun., 1986, pp. 105-120.

Azuela, Antonio, Presentación a la ley de expropiación de predios urbanos en el Distrito Federal, vol. 48, núm. 2, abr.-jun., 1986, pp. 304-305.

Barbicri, Teresita de Guzmán Carlota, Los damnificados y el empleo, vol. 48, núm. 2, abr.-jun.. 1986, pp. 59-101.

Bejarano González. Fernando, Las irregularidades de la tenencia de la tierra en las colonias populares (1976-1986). vol. 4.5, núm. 3, jul.sept., 1983, pp. 797-827.

Boils, Guillermo, La producción social del espacio en Cuba: 20 años de revolución urbana, vol. 43, núm. 4. oct.-dic.. 1981, pp. 1487-1501.

Boils, Guillermo. A suelo revuelto ganancia de arrendadores, vol. 48, núm. 2. abr.-jun., 1986, pp. 239-247.

Borja. Jordi, Movimientos urbanos y cambio político, vol. 43, núm. 4, oct.-dic., 1981. pp. 1341-1369.

Borja, Jordi, Politica municipal, la izquierda cumplió 60 años, vol. 44, núm. 1. ene.-mar., 1982, pp. 31-51.

Borja. Jordi. Descentralización. Una cuestión de método, vol. 46, núm. 4, oct.-dic.. 1984, pp. 5-33.

Boria. Jordi, Transformaciones territoriales e instituciones en Europa, vol. 48, núm. 4. oct.-dic.. 1986, pp. 225-257.

Camarena Luhrs. Margarita, El transporte urbano en condiciones de emergencia, vol. 48, núm. 2. abr.-jun.. 1986.

Castells. Manuel Proposiciones teóricas para una investigación experimental sobre los movimientos sociales urbanos, vol. 34, núm. 1, ene.-mar., 1972, pp. 1-26.

Castells, Manuel. Apuntes para un análisis de clase de la política urbana del estado mexicano, vol. 39, núm. 4, oct.-dic., 1977, pp. 1161-1191.

Castells Manuel, La crisis, la planificación y la calidad de la zida: el manejo de las nuevas relaciones históricas entre espacio y' sociedad, vol. 46, núm. 4. oct.-dic., 1984, pp. 35-65.

Castillo Berthier, Héctor, El mercado de La Merced antes del cambio, vol. 45, núm. 3, jul.-sept.. 1983, pp. 857-875.

Contreras Suárez, Enrique, Inestabilidad ocupacional y estratificación urbanas, vol. 33, núm. 4, oct.-dic., 1971, pp. 699-728.

Contreras Suárez. Enrique, Movilidad individual y oportunidades de empleo en la ciudad de México, vol. 36, núm. 2, abr.-jun., 1974, pp. 297-341. 
Contreras Suárez, Enrique, El flujo migratorio hacia la ciudad de México, vol. 37, núm. 3, jul.-sept., 1975, pp. 789-819.

Dalmasso, E. y P. Fillon, Aspectos de la organización espacial del Ecuador, vol. 34, núm. 1, ero.-mar., 1972, pp. 75-94.

Eckstein, Susan, Las ciudades en Cuba socialista, vol. 40, núm. 1, ene.mar., 1978, pp. 155-180.

Espinosa, Vicente; Alfredo Rodríguez y Alex Rosenfeld, Poder local, pobladores y democracia, vol. 48, núm. 4, oct.-dic., 1986, pp. 123-140.

Evers, Tilman, Síntesis interpretativa del "Movimiento do custo de vida" un movimiento urbano brasileño, vol. 43, núm. 4, oct.-dic., 1981, pp. 1371-1393.

Evers Tilman; Clarita Muller-Plantenberg y Stefanie Spessart, Movimientos barriales y estado. Luchas en la esfera de la reproducción en América Latina, vol. 44, núm. 2, abr.-jun., 1982, pp. 703-756.

Fadda Cori, Giulietta, Crisis urbana en el área metropolitana de Caracas, vol. 48, núm. 4, oct.-dic., 1986, pp. 87-108.

Faria, Vilmar, Del sistema urbano en el Brasil. Resumen de las caracteristicas y tendencias recientes, vol. 43, núm. 1, oct.-dic., 1981, pp. 1415-1438.

Faria, Vilmar, Una tipología empirica de las ciudades brasileñas (un análisis preliminar), vol. 44, núm. 1, ene.-mar., 1982, pp. 53-79.

Feder, Ernest, La pobreza y el desempleo en América Latina: un reto para la investigación sacio-económica, vol. 36, núm. 1, ene.-mar., 1974, pp. 1-44.

García, Brígida; Humberto Muñoz y Orlandina de Oliveira, Migraciones internas y grupos populares urbanos. Ciudad de México, vol. 40, núm. 1, ene.-mar., 1978, pp. 107-129.

García Peralta, Beatriz, Estado y capital privado en el fraccionamiento Izcalli-Chamapa, vol. 43, núm. 4, oct.-dic., 1981, pp. 1439-1464.

García Peralta, Beatriz, La vivienda en las delegaciones afectadas por los sismos, vol. 48, núm. 2, abr.-jun., 1986, pp. 283-291.

Gugler, Joseph, Un minimo de urbanismo y un máximo de ruralismo: la experiencia cubana, vol. 43, núm. 4, oct.-dic., 1981, pp. 1465-1486.

Grajales, Carolina y Lara Rosano, Felipe, Las decisiones politicas en transporte: el caso del Aeropuerto de la Ciudad de México, vol. 45, núm. 3, jul.-sept., 1983, pp. 915-932.

Jacobi, Pedro, Säo Paulo: las luchas de los excluidos de la ciudad por el derecho a la ciudadanía 1970-1982, vol. 46, núm. 4, oct.-dic., 1984, pp. 191-209.

Jaramillo, Samuel y Martha Schteingart, Procesos sociales y producción de vivienda en América Latina 1960-1980, vol. 45, núm. 1, ene.-mar., 1983, pp. 11-28.

Lomnitz, Larissa, Mecanismos de articulación entre el sector informal y el sector formal urbano, vol. 40, núm 1, ene.-mar., 1978, pp. 131-153. 
Kowarick, Lucio, Desarrollo capitalista y marginalidad: el caso brasileño, vol. 40, núm. 1, ene.-mar., 1978, pp. 31-54.

Kowarick, Lucio, Los caminos del encuentro, vol. 46, núm. 4, oct-dic., 1984, pp. 67-83.

Kusnetzoff, Fernando, Democratización del Estado, gobiernos locales y cambio social. Experiencias comparativas en Chile y Nicaragua, vol. 45, núm. 1, ene.-mar., 1983, pp. 191-219.

Machado, Luis y Magalaes, Paulo, Mata Machado: aspectos de las luchas sociales en una favela carioca, vol. 46, núm. 4, oct.-dic., 1984, pp. 173-189.

Massolo, Alejandra, La organización de los damnificados (;Que el gobierno entienda, primero es la vivienda!), vol. 48, núm. 2, abr.-jun., 1986, pp. 195-238.

Martínez Assad, Carlos y Ziccardi Alicia, El municipio entre la sociedad y el Estado, vol. 48, núm. 4, oct.-dic., 1986, pp. 7-49.

Mauro, Frederic, El rol de las ciudades en el desarrollo regional en América Latina, vol. 34, núm. 1, ene.-mar., 1972, pp. 65-73.

Mier y Terán, Martha y Cecilia Rabell, Los damnificados en la ciudad de México, vol. 48, núm. 2, abr.-jun., 1986, pp. 3-28.

Moisés, José, Clases populares y politicas en Brasil, vol. 40, núm. 4, oct.dic., 1978, pp. 1429-1451.

Mosquera Torres, Gilma, El movimiento de los destechados colombianos en la década del 70, vol. 46, núm. 4, oct.-dic., 1984, pp. 127-144.

Muñoz, Humberto y Orlandina de Oliveira, Migración, oportunidades de empleo y diferencias de ingreso en la ciudad de México, vol. 38, núm. 1, ene.-mar., 1976, pp. 51-83.

Navarro, Bernardo, El metro y la ciudad de México, vol. 46, núm. 4, oct.-dic., 1984, pp. 85-102.

Nunes, Edison, Movimientos y prácticas urbanas en Brasil, vol. 48, núm. 4, oct.-dic., 1986, pp. 73-86.

Perló, Cohen, Manuel, Política y vivienda en México: 1910-1952, vol. 41, núm. 3, jul.-sept., 1979, pp. 769-835.

Perló, Manuel y Martha Schteingart, Movimientos sociales urbanos en México, algunas reflexiones en torno a la relación procesos sociales urbanos. Respuestas de los sectores populares, vol. 46, núm. 4, oct.dic., 1984, pp. 105-125.

Pirez, Pedro, Coparticipación federal y descentralización del Estado Federal, vol. 48, núm. 4, oct.-dic., 1986, pp. 175-224.

Quilodrán, Julieta, Acerca del estado civil de los refugiados en albergues, vol. 48, núm. 2, abr.-jun., 1986, pp. 29-57.

Rivera, Alberto, Municipio y problemas urbanos en Bolivia, vol. 48, núm. 4, oct.-dic., 1986, pp. 109-121.

Rodríguez A., Alfredo, De qué modo hay que gobernar las ciudades o principados que, antes de ser ocupados se regían por sus propias leyes, vol. 45, núm. 1, ene.-mar., 1983, pp. 29-43. 
Viviescas M. Fernando, Identidad municipal y cultura urbana, vol. 48, núm. 4, oct.-dic., 1986, pp. 51-71.

Zermeño, Sergio, Ocoyoacac: triunfo de la política, vol. 49, núm. 4, oct.dic., 1937, pp. 75-109.

Ziccardi, Alicia, Villas, miseria y favelas: sobre las relaciones entre las instituciones del Estado y la organización social en las democracias de los años sesenta, vol. 45, núm. 1, ene.-mar., 1983, pp. 45-67.

Ziccardi, Alicia, El tercer gobierno peronista y las villas miseria de la ciudad de Buenos Aires (1973-1976), vol. 46, núm. 4, oct.-dic., 1984, pp. 145-172.

Ziccardi, Alicia, Politica de vivienda para un espacio destruido, vol. 48, núm. 2, abr.-jun., 1986, pp. 121-193. 